\title{
Transbilayer Complementarity of Phospholipids: Proof of Principle
}

\author{
Jianbing Zhang, Bingwen Jing, and Steven L. Regen* \\ Department of Chemistry, Lehigh University, Bethlehem, Pennsylvania 18015
}

\section{Supporting Information}

18 Lyso PE-BOC (N-(tert-Butoxycarbonyl)-1-stearoyl-2-hydroxy-sn-glycero-3-

phosphoethanolamine). To a solution of $700 \mathrm{mg}$ (1.45 mmol) of 1-stearoyl-sn-glycero-3phosphoethanolamine (18 lysoPE) in $15 \mathrm{~mL}$ of chloroform-methanol $(2 / 1, \mathrm{v} / \mathrm{v})$ was added $429 \mathrm{mg}$ (1.74 mmol) BOC-ON, and $404 \mu \mathrm{L}$ (2.90 mmol) of triethylamine. The resulting mixture was stirred for $6 \mathrm{~h}$ at room temperature, concentrated under reduced pressure and the residue purified by silica gel column chromatography, using chloroform-methanol (5/1, v/v) as an eluant, affording $728 \mathrm{mg}$ of the corresponding BOC-protected lyso PE in 86\% isolated yield, having ${ }^{1} \mathrm{HNMR}\left(\mathrm{CD}_{3} \mathrm{OD} / \mathrm{CDCl}_{3} ; 1 / 1\right.$, v/v, $\left.500 \mathrm{MHz}\right): 0.84(\mathrm{t}, 3 \mathrm{H})$, 1.24(m, 28H), 1.41(s, 9H), 1.59(m, 2H), 2.32(t, 2H), 3.15(t, 2H), 3.58(t, 2H), 3.804.50(m, 5H).

1812 PE-BOC (N-(tert-Butoxycarbonyl)-1-stearoyl-2-lauroyl-sn-glycero-3phosphoethanolamine). A mixture containing lauric acid (1.0 g, 4.99 mmol), imidazole (407 mg, $5.99 \mathrm{mmol})$ and DCC (1.236 g, $5.99 \mathrm{mmol}$ ) was stirred for $5 \mathrm{~h}$ at room temperature, followed by removal of the urea by filtration. The filtrate was concentrated 
under reduced pressure and the residue (i.e., activated lauric acid) dried overnight by use of a freeze dryer. This activated lauric acid was dissolved in $15 \mathrm{~mL}$ of chloroform, followed by addition of BOC-protected 18 lyso PE (728 mg, $1.25 \mathrm{mmol}$ ) and DBU (747 $\mu \mathrm{L}, 4.99 \mathrm{mmol}$ ). After stirring overnight at room temperature, the mixture was poured into $50 \mathrm{~mL}$ of $10 \% \mathrm{HCl}$ and extracted with $3 \times 30 \mathrm{~mL}$ of chloroform. The organic layers were combined and concentrated under reduced pressure. Subsequent purification of the residue by silica gel column chromatography, using chloroform/methanol/water (60/10/1, $\mathrm{v} / \mathrm{v} / \mathrm{v}$ ) as the eluant gave $811 \mathrm{mg}$ (85 \%) of 1812 PE-BOC having $\mathrm{R}_{\mathrm{f}}=0.65$ and ${ }^{1} \mathrm{HNMR}$ $\left(\mathrm{CD}_{3} \mathrm{OD} / \mathrm{CDCl}_{3} ; 1 / 1, \mathrm{v} / \mathrm{v}, 500 \mathrm{MHz}\right): 0.85(\mathrm{t}, 6 \mathrm{H}), 1.24(\mathrm{~m}, 44 \mathrm{H}), 1.40(\mathrm{~s}, 9 \mathrm{H}), 1.57(\mathrm{~m}$, 4H), 2.28(q, 4H), 3.28(t, 2H), 3.85(q, 2H), 3.95(t, 2H), 4.15(q, 1H), 4.40(m, 1H), 5.20(m, $1 \mathrm{H})$.

1812 PE (1-Stearoyl-2-lauroyl-sn-glycero-3-phosphoethanolamine). To solution of 1812 PE-BOC (743 mg, $0.973 \mathrm{mmol})$ in $10 \mathrm{~mL}$ of chloroform at ${ }^{0} \mathrm{C}$ was added $5 \mathrm{~mL}$ of trifluoroacetic acid. After stirring overnight at room temperature, the solvent was removed under reduced pressure and the residue purified by silica gel column chromatography using 40/10/1 (v/v/v) chloroform/methanol/ammonium hydroxide as the eluant to give $523 \mathrm{mg}$ (81\%) of $1812 \mathrm{PE}$ having $\mathrm{R}_{\mathrm{f}}=0.45$ and ${ }^{1} \mathrm{HNMR}\left(\mathrm{CDCl}_{3}, 45{ }^{\circ} \mathrm{C}\right.$, $500 \mathrm{MHz})$ : 0.87(t, 6H), 1.25(m, 44H), 1.57 (m, 4H), 2.27(m, 4H), 3.19(s, 2H), 3.94 (s, 2H), 4.12(m, 3H), 4.35(d, 1H), 5.20(s, 1H).

1414 Non-exchangeable monomer. To a solution containing $0.2 \mathrm{mmol}$ (41 mg) of 2,2'(ethylenedithio)diacetic acid and $0.1 \mathrm{mmol}(11.5 \mathrm{mg})$ of $\mathrm{N}$-hydroxysuccinimide in $15 \mathrm{~mL}$ of THF was added $0.1 \mathrm{mmol}(21 \mathrm{mg})$ of DCC. After stirring at $\mathrm{rt}$ for $4 \mathrm{~h}$, the solvent was 
removed under reduced pressure and the residue dissolved in $5 \mathrm{~mL}$ of chloroform, followed by addition of $0.1 \mathrm{mmol}$ (63.5 mg) of 1,2-dimyristoyl-sn-glycero-3phosphoethanolamine (1414PE) plus $0.3 \mathrm{mmol}(41 \mu \mathrm{L})$ of triethylamine. After stirring for $5 \mathrm{~h}$, the solution was diluted with chloroform and washed with $10 \% \mathrm{HCl}$. The organic layer was collected and dried over anhydrous $\mathrm{MgSO}_{4}$. Removal of solvent under reduced pressure, followed by preparative thin layer chromatography using chloroform/methanol/water (65/25/4, v/v/v) as the eluant afforded $54 \mathrm{mg}$ (65\%) of the 1414 nonexchangeable monomer having $\mathrm{R}_{\mathrm{f}}=0.35$ and ${ }^{1} \mathrm{HNMR}\left(\mathrm{CDCl}_{3}, 500 \mathrm{MHz}\right)$ : 0.84(t, 6H), 1.23(m, 40H), 1.56(m, 4H), 2.30(hex, 4H), 2.79-2.86(hex, 4H), 3.23(s, 2H), 3.30(s, 2H), 3.56(s, 2H), 4.14(m, 5H), 4.32(m, 1H), 5.22(m, 1H), 7.69(s, 1H), 9.92(s, $1 \mathrm{H})$.

Similar procedures were used for the synthesis of the following monomers:

1818 non-exchangeable monomer. ${ }^{1} \mathrm{HNMR}\left(\mathrm{CDCl}_{3}, 500 \mathrm{MHz}\right): 0.85(\mathrm{t}, 6 \mathrm{H}), 1.23(\mathrm{~m}$, 56H), 1.57(m, 4H), 2.30(hex, 4H), 2.79-2.86(hex, 4H), 3.23(s, 2H), 3.30(s, 2H), 3.57(s, 2H), 4.15(m, 5H), 4.33(m, 1H), 5.23(m, 1H), 7.64(br, 1H), 8.43(br, 1H).

1414 exchangeable monomer. ${ }^{1} \mathrm{HNMR}\left(\mathrm{CDCl}_{3}, 500 \mathrm{MHz}\right): 0.85(\mathrm{t}, 6 \mathrm{H}), 1.23(\mathrm{~m}, 40 \mathrm{H})$, 1.56(m, 4H), 2.28(m, 4H), 2.60(t, 2H), 2.66(t, 2H), 2.94(m, 4H), 3.44(s 2H), 3.98(m, 4H), 4.12(m, 1H), 4.35(d, 1H), 5.19(s, 1H), 7.42(br, 1H), 9.40(br, 1H).

1818 exchangeable monomer. ${ }^{1} \mathrm{HNMR}\left(\mathrm{CDCl}_{3}, 500 \mathrm{MHz}\right): 0.85(\mathrm{t}, 6 \mathrm{H}), 1.23(\mathrm{~m}, 56 \mathrm{H})$, 1.56(m, 4H), 2.28(m, 4H), 2.62(m, 4H), 2.94(m, 2H), 3.43(s, 2H), 3.88(m, 4H), 4.12(m, 1H), 4.35(d, 1H), 5.19(s, 1H), 7.32(br, 1H), 9.43(br, 1H).

Synthesis of 1812-1414 non-exchangeable dimer (A'C'). To a solution of $1414 \mathrm{PE}$ nonexchangeable monomer (41 mg, $0.05 \mathrm{mmol}$ ) and N-hydroxysuccinimide (7 mg, 0.06 
$\mathrm{mmol})$ in $4 \mathrm{~mL}$ of chloroform was added DCC (12 mg, $0.06 \mathrm{mmol})$. After stirring for $2 \mathrm{~h}$, $33 \mathrm{mg}(0.05 \mathrm{mmol})$ of $1812 \mathrm{PE}$ and $21 \mu \mathrm{L}(0.15 \mathrm{mmol})$ of triethylamine were added. The mixture was stirred for an additional $4 \mathrm{~h}$, diluted with $20 \mathrm{~mL}$ of chloroform and washed with a $10 \%$ aqueous $\mathrm{HCl}$ solution. The organic layer was collected and dried over anhydrous $\mathrm{MgSO}_{4}$. Subsequent purification by preparative thin layer chromatography, using chloroform/ methanol/ water (30/10/1, v/v/v) as the eluant afforded $54 \mathrm{mg}(73 \%)$ of $\mathbf{A}^{\prime} \mathrm{C}^{\prime}$ having $\mathrm{R}_{\mathrm{f}}=0.44$ and ${ }^{1} \mathrm{HNMR}\left(\mathrm{CDCl}_{3}, 500 \mathrm{MHz}\right): 0.85(\mathrm{t}, 12 \mathrm{H}), 1.23(\mathrm{~m}, 84 \mathrm{H})$, 1.55(m, 8H), 2.27(m, 8H), 2.79 (s, 4H), 3.26(s, 4H), 3.46(s, 4H), 3.89(m, 8H), 4.13(m, 2H), 4.37(d, 2H), 5.18(s, 2H), 7.95(br, 2H). LRMS (MALDI) $\left[\mathrm{M}-2 \mathrm{H}^{+}+3 \mathrm{Na}^{+}\right]^{+} \mathrm{m} / \mathrm{z}$, 1540.

Similar procedures were used for the synthesis of the dimers shown below:

1812-1812 non-exchangeable dimer ( $\left.\mathrm{C}^{\prime} \mathrm{C}^{\prime}\right) .{ }^{1} \mathrm{HNMR}\left(\mathrm{CDCl}_{3}, 500 \mathrm{MHz}\right): 0.85(\mathrm{t}, 12 \mathrm{H})$, 1.23(m, 88H), 1.55(m, 8H), 2.28(m, 8H), 2.79(s, 4H), 3.26(s, 4H), 3.47(s, 4H), 3.89(m, 8H), 4.12(m, 2H), 4.37(d, 2H), 5.18(s, 2H), 7.96(br, 2H). LRMS (MALDI) [M-2H +3 $\left.\mathrm{Na}^{+}\right]^{+} m / z, 1568$.

1812-1818 Non-exchangeable dimer (B'C'). ${ }^{1} \mathrm{HNMR}\left(\mathrm{CDCl}_{3}, 500 \mathrm{MHz}\right):(0.85(\mathrm{t}, 12 \mathrm{H})$, 1.23(m, 100H), 1.56(m, 8H), 2.28(m, 8H), 2.79(s, 4H), 3.26(s, 4H), 3.45(s, 4H), 3.88(m, 8H), 4.13(m, 2H), 4.37(d, 2H), 5.18(s, 2H), 7.98(br, 2H). LRMS (MALDI) [M-2H+ +3 $\left.\mathrm{Na}^{+}\right]^{+} m / z, 1652$.

1812-1812 exchangeable dimer (CC). ${ }^{1} \mathrm{HNMR}\left(\mathrm{CDCl}_{3}, 500 \mathrm{MHz}\right): 0.85(\mathrm{t}, 12 \mathrm{H}), 1.23(\mathrm{~m}$, 88H), 1.55(m, 8H), 2.28(m, 8H), 2.60(m, 4H), 2.97(m, 4H), 3.42(s, 4H), 3.86(m, 8H), 4.12(m, 2H), 4.37(d, 2H), 5.18(s, 2H), 7.73(br, 2H). LRMS (MALDI) $\left[\mathrm{M}-2 \mathrm{H}^{+}+3 \mathrm{Na}^{+}\right]^{+}$ $m / z, 1568$. 
1812-1414 exchangeable dimer (AC). ${ }^{1} \mathrm{HNMR}\left(\mathrm{CDCl}_{3}, 500 \mathrm{MHz}\right): 0.87(\mathrm{t}, 12 \mathrm{H}), 1.27(\mathrm{~m}$, 84H), 1.57(m, 8H), 2.28(m, 8H), 2.62(t, 4H), 2.99(t, 4H), 3.45(s, 4H), 3.88(m, 8H), 4.14(m, 2H), 4.39(d, 2H), 5.19(s, 2H), 7.54(br, 2H). LRMS (MALDI) $\left[\mathrm{M}-2 \mathrm{H}^{+}+3 \mathrm{Na}^{+}\right]^{+}$ $m / z, 1540$.

1812-1818 exchangeable dimer (BC). ${ }^{1} \mathrm{HNMR}\left(\mathrm{CDCl}_{3}, 500 \mathrm{MHz}\right): 0.87(\mathrm{t}, 12 \mathrm{H}), 1.25(\mathrm{~m}$, 100H), 1.57(m, 8H), 2.28(m, 8H), 2.62(t, 4H), 2.99(t, 4H), 3.45(s, 4H), 3.92(m, 8H), 4.14(m, 2H), 4.39(d, 2H), 5.19(s, 2H), 7.55(br, 2H). LRMS (MALDI) $\left[\mathrm{M}-2 \mathrm{H}^{+}+3 \mathrm{Na}^{+}\right]^{+}$ $m / z, 1652$.

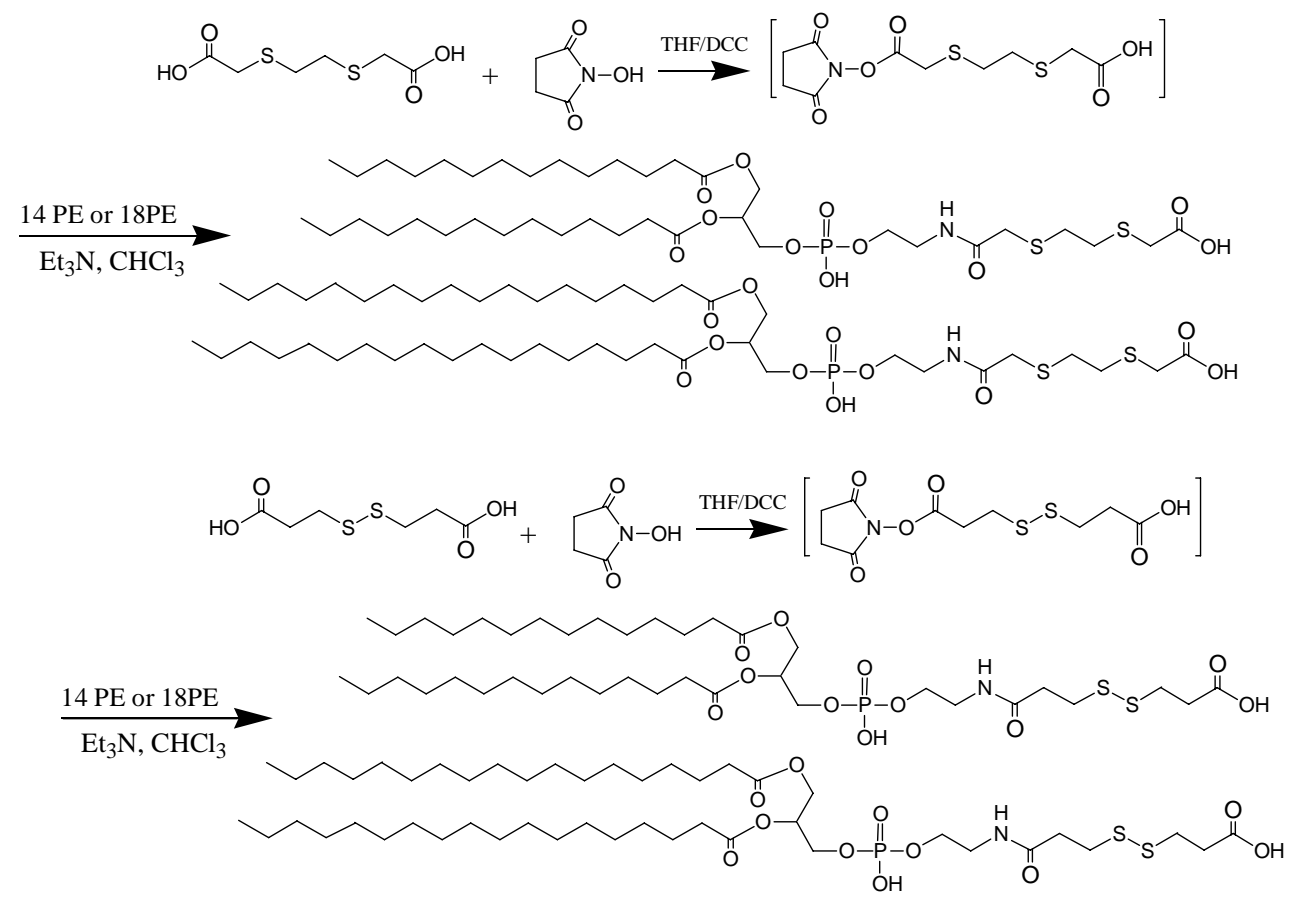




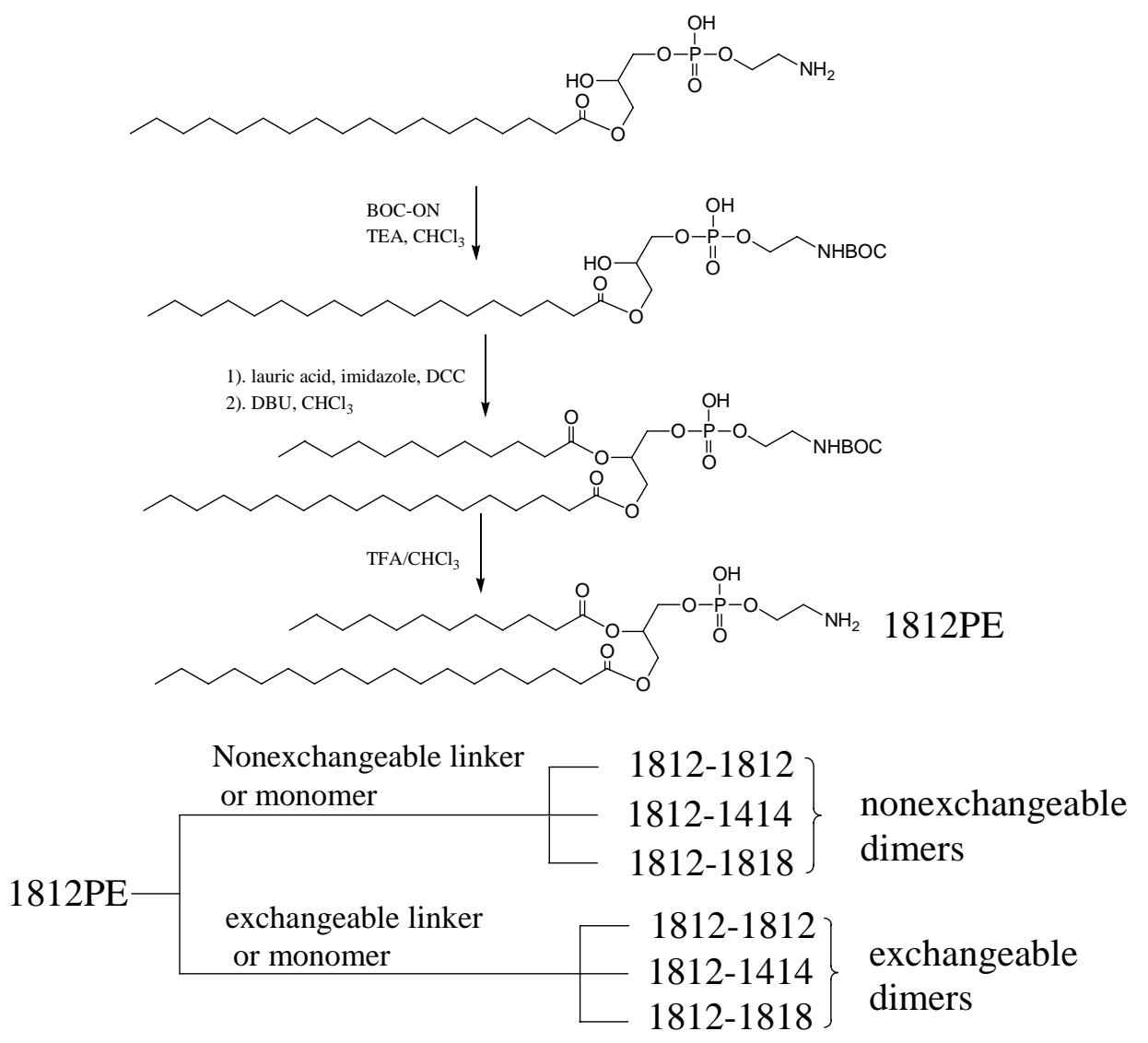

Quantification of Dimer Distributions. As discussed in the text, the interchange of monomers of $\mathbf{A}, \mathbf{B}$ and $\mathbf{C}$ among $\mathbf{A A}, \mathbf{B B}$ and $\mathbf{C C}$ or $\mathbf{A B}$ and $\mathbf{C C}$ is governed by an equilibrium constants, $K_{1}, K_{2}$ and $K_{3}$, which characterize their mixing behaviors (eqs 1 to $6)$. 

$\mathrm{AA}+\mathrm{BB}+\mathrm{CC} \rightarrow \mathrm{AA}+\mathrm{AB}+\mathrm{BB}+\mathrm{AC}+\mathrm{BC}+\mathrm{CC} \leftarrow \mathrm{AB}+\mathrm{CC}$
$\mathrm{AA}+\mathrm{BB} \rightleftharpoons 2 \mathrm{AB} \quad \mathrm{K}_{1}$
(1)
$\mathrm{AA}+\mathrm{CC} \rightleftharpoons 2 \mathrm{AC} \quad \mathrm{K}_{2}$
$\mathrm{BB}+\mathrm{CC} \rightleftharpoons 2 \mathrm{BC} \rightleftharpoons \mathrm{K}_{3}$
$\mathrm{K}_{1}=\frac{[\mathrm{AB}]^{2}}{[\mathrm{AA}][\mathrm{BB}]}$
$\mathbf{K}_{2}=\frac{[\mathrm{AC}]^{2}}{[\mathrm{AA}][\mathrm{CC}]}$
$\mathbf{K}_{3}=\frac{[\mathrm{BC}]^{2}}{[\mathrm{BB}][\mathrm{CC}]}$

Because $\mathbf{C}^{\prime} \mathbf{C}^{\prime}$ and $\mathbf{C C}, \mathbf{A}^{\prime} \mathbf{C}^{\prime}$ and $\mathbf{A C}$, and $\mathbf{B}^{\prime} \mathbf{C}^{\prime}$ and $\mathbf{B C}$, overlapped in the HPLC traces, dimer concentrations $[\mathbf{C C}],[\mathbf{A C}]$, and $[\mathbf{B C}]$ were used to calculate $K$ values when A'A', B'B' and A'B' were employed as the templates, respectively, as outlined below: Experiments using $20 \mathrm{~mol} \% \mathbf{C}^{\prime} \mathbf{C}^{\prime}$. Liposomes were prepared using 30\% AA, 30\% BB, $20 \% \mathbf{C C}$ and $20 \% \mathbf{C}^{\prime} \mathbf{C}^{\prime}$ and also $60 \% \mathbf{A B}, 20 \% \mathbf{C C}$ and $20 \% \mathbf{C}^{\prime} \mathbf{C}^{\prime}$. In both cases, the molar ratio of $\mathbf{C}^{\prime} \mathbf{C}^{\prime} / \mathbf{C C}$ equals $1 / 1$. Since essentially all of the phospholipids are in the dimer form at the end of the exchange reaction, the mass balance in these systems can be expressed according to equation 7 . Here, $[\mathbf{C C}],[\mathbf{A C}]$ and $[\mathbf{B C}]$ refer to the dimer concentrations that are present when equilibrium is reached, and $[\mathbf{C C}]_{0}$ is the starting concentrations of the exchangeable dimer.

$$
\frac{\left[\mathrm{C}^{\prime} \mathrm{C}^{\prime}\right]}{[\mathrm{CC}]_{0}}=\frac{\left[\mathrm{C}^{\prime} \mathrm{C}^{\prime}\right]}{[\mathrm{CC}]+\frac{1}{2}[\mathrm{AC}]+\frac{1}{2}[\mathrm{BC}]}=\frac{1}{1}
$$


Equation 8 is a rearranged form of eq 7, that expresses $\left[\mathbf{C}^{\prime} \mathbf{C}^{\prime}\right]$ in terms of $[\mathbf{C C}],[\mathbf{A C}]$ and [BC]. From the HPLC analysis, one can readily measure the concentration of the sum of CC and $\mathbf{C}^{\prime} \mathbf{C}^{\prime}$, as shown in eq 9.

$$
\begin{aligned}
& {\left[C^{\prime} C^{\prime}\right]=[C C]+\frac{1}{2}[A C]+\frac{1}{2}[B C]} \\
& {\left[C^{\prime} C^{\prime}\right]+[C C]=S_{1}}
\end{aligned}
$$

If we now combine eqs 8 and 9 and eliminate $\mathbf{C}^{\prime} \mathbf{C}$ ' term, one may obtain eq 10, that expresses $[\mathbf{C C}]$ in terms of the sum of $[\mathbf{C C}]$ and $\left[\mathbf{C}^{\prime} \mathbf{C}^{\prime}\right],[\mathbf{A C}]$ and $[\mathbf{B C}]$.

$$
[C C]=\frac{1}{4}\left(2 S_{1}-[A C]-[B C]\right)
$$

The standard deviation of [CC] can then be calculated based on the standard error transfer formula according to eqs. 11 and 12 . Thus, if $\mathrm{x}_{1}, \mathrm{x}_{2}, \ldots \mathrm{x}_{\mathrm{n}}$ are experimentally measured values, and $y$ is calculated from these values using the formula, $y=f\left(x_{1}, x_{2}, \ldots\right.$. $\mathrm{x}_{\mathrm{n}}$ ), then the standard deviation of $\mathrm{y}$ is given by eq 12 .

$$
\begin{aligned}
& y=f\left(x_{1}, x_{2}, \ldots . . x_{n}\right) \\
& \text { dy }=\frac{\partial f}{\partial x_{1}} d x_{1}+\frac{\partial f}{\partial x_{2}} d x_{2}+\ldots \ldots . .+\frac{\partial f}{\partial x_{n}} d x_{n}
\end{aligned}
$$

Equation 13, which is obtained by using eq 12 on eq 10, represents the standard deviation of $[\mathbf{C C}]$. 


$$
\mathrm{d}[\mathrm{CC}]=\frac{1}{4}\left(2 \mathrm{dS}_{1}-\mathbf{d}[\mathrm{AC}]-\mathbf{d}[\mathrm{BC}]\right)
$$

Experiments using 20 mol\% A'C'. Liposomes were prepared using 20\% A'C', 20\% AA, $30 \%$ BB, and $30 \%$ CC, and also $20 \%$ A'C' $^{\prime}, 40 \%$ AB, $10 \%$ BB and $30 \%$ CC. In both cases, the molar ratio of template $\mathbf{A}^{\prime} \mathbf{C}^{\prime}$ to the sum of the exchangeable dimers is $1 / 4$, as shown in eq 14. This ratio simply reflects the mass balance in the system, and is constant provided that the thiol monomer content is negligible, which has been found to be the case. In eq $14,[\mathbf{A A}]_{\mathrm{o}},[\mathbf{B B}]_{\mathrm{o}},[\mathbf{A B}]_{\mathrm{o}}$ and $[\mathbf{C C}]_{\mathrm{o}}$ refer to the starting concentrations of the exchangeable dimers, and $[\mathbf{A A}],[\mathbf{B B}],[\mathbf{A B}],[\mathbf{A C}],[\mathbf{B C}]$ and $[\mathbf{C C}]$ are the final equilibrium concentrations.

$$
\frac{\left[\mathrm{A}^{\prime} \mathrm{C}^{\prime}\right]}{[\mathrm{AA}]_{0}+[\mathrm{BB}]_{0}+[\mathrm{CC}]_{0}}=\frac{\left[\mathrm{A}^{\prime} \mathrm{C}^{\prime}\right]}{[\mathrm{AA}]+[\mathrm{AB}]+[\mathrm{BB}]+[\mathrm{AC}]+[\mathrm{BC}]+[\mathrm{CC}]}=\frac{1}{4}
$$

eq 14 can also be expressed as eq 15, that expresses [A' $\left.\mathbf{C}^{\prime}\right]$ in terms of [AA], [AB], [BB], [AC], $[\mathbf{B C}]$ and $[\mathbf{C C}]$. From the HPLC analysis, one can readily measure the concentration of the sum of $\mathbf{A C}$ and $\mathbf{A}^{\prime} \mathbf{C}^{\prime}$, as shown in eq 16.

$$
\begin{aligned}
& {\left[A^{\prime} C^{\prime}\right]=\frac{1}{4}([A A]+[A B]+[B B]+[A C]+[B C]+[C C])} \\
& {\left[A^{\prime} C^{\prime}\right]+[A C]=S_{2}}
\end{aligned}
$$


If we now combine eqs 15 and 16 and eliminate $\mathbf{A}^{\prime} \mathbf{C}^{\prime}$ term, one may obtain eq 17, that expresses $[\mathbf{A C}]$ in terms of the sum of $[\mathbf{A C}]$ and $\left[\mathbf{A}^{\prime} \mathbf{C}^{\prime}\right],[\mathbf{A A}],[\mathbf{B B}],[\mathbf{A B}],[\mathbf{B C}]$ and [CC]. Equation 18, which is obtained by using eq 12 on eq 17, represents the standard deviation of $[\mathbf{A C}]$.

$$
\begin{aligned}
& {[A C]=\frac{1}{5}\left(4 S_{2}-[A A]-[A B]-[B B]-[B C]-[C C]\right)} \\
& d[A C]=\frac{1}{5}\left(4 d S_{2}-d[A A]-d[A B]-d[B B]-d[B C]-d[C C]\right)
\end{aligned}
$$

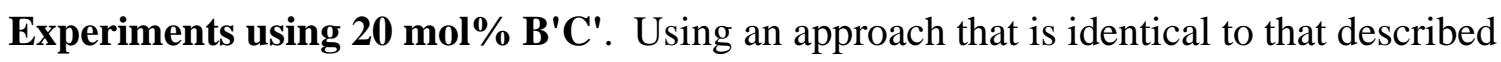
above, eqs 19, 20 and 21 are applicable when $\mathbf{B}^{\prime} \mathbf{C}^{\prime}$ is used as the template:

$$
\begin{aligned}
& {[B C]+\left[B^{\prime} C^{\prime}\right]=S_{3}} \\
& {[B C]=\frac{1}{5}\left(4 S_{3}-[A A]-[A B]-[B B]-[A C]-[C C]\right)} \\
& d[B C]=\frac{1}{5}\left(4 d S_{3}-d[A A]-d[A B]-d[B B]-d[A C]-d[C C]\right)
\end{aligned}
$$


The experimental conditions that were used to obtain all of the data that appear in the following tables, including the conditions used for equilibration, the total concentrations of lipid used, the buffer composition, and the exchange catalyst are described in the Experimental Section of the paper:

Table S1. Equilibrium Dimer Concentrations in the Absence of Template

\begin{tabular}{ccccccc}
\hline & \multicolumn{7}{c}{ Product mixture (mol\%) } \\
\cline { 2 - 7 } Time, h & AA & AC & CC & AB & BC & BB \\
\hline \multicolumn{7}{c}{ Starting from AA, BB and CC } \\
1 & 15.99 & 16.50 & 23.84 & 10.96 & 16.88 & 15.84 \\
2 & 8.784 & 24.60 & 17.38 & 15.55 & 25.09 & 8.589 \\
3 & 8.702 & 24.35 & 17.69 & 16.84 & 23.93 & 8.486 \\
4 & 8.620 & 24.74 & 16.80 & 16.63 & 24.54 & 8.672 \\
5 & 8.614 & 25.09 & 17.43 & 16.73 & 23.84 & 8.289 \\
6 & 8.608 & 24.54 & 17.82 & 16.52 & 24.45 & 8.074 \\
\multicolumn{7}{c}{ Starting from AB and CC } \\
1 & 5.392 & 15.30 & 27.15 & 3.227 & 14.48 & 5.406 \\
2 & 8.244 & 24.11 & 18.64 & 16.71 & 24.22 & 8.075 \\
3 & 8.376 & 24.45 & 18.08 & 16.38 & 24.62 & 8.106 \\
4 & 8.278 & 24.49 & 18.06 & 16.63 & 24.34 & 8.196 \\
5 & 8.541 & 24.92 & 18.01 & 16.80 & 23.40 & 8.327 \\
6 & 8.595 & 24.62 & 18.11 & 16.70 & 23.92 & 8.050 \\
\hline \multicolumn{7}{c}{}
\end{tabular}


Table S2. Equilibrium Dimer Concentrations in the presence of $\mathrm{C}^{\prime} \mathrm{C}^{\prime}$

\begin{tabular}{ccccccc}
\hline & \multicolumn{7}{c}{ Product mixture (mol\%) } \\
\cline { 2 - 7 } Time, h & AA & AC & CC & AB & BC & BB \\
\hline \multicolumn{7}{c}{ Starting from AA, BB and CC } \\
1 & 20.74 & 12.42 & 17.59 & 15.02 & 9.67 & 24.55 \\
2 & 13.50 & 17.60 & 13.48 & 26.88 & 15.36 & 13.17 \\
3 & 13.34 & 17.81 & 12.37 & 26.43 & 16.44 & 13.60 \\
4 & 13.11 & 17.87 & 11.23 & 26.63 & 17.94 & 13.23 \\
5 & 12.93 & 18.18 & 12.45 & 25.97 & 17.08 & 13.39 \\
6 & 12.93 & 17.28 & 11.59 & 27.33 & 17.82 & 13.04 \\
& & \multicolumn{7}{c}{ Starting from AB and CC } \\
1 & 6.981 & 10.56 & 20.57 & 44.84 & 9.229 & 7.813 \\
2 & 13.03 & 17.76 & 13.52 & 26.60 & 16.12 & 12.97 \\
3 & 12.48 & 18.39 & 12.74 & 25.94 & 17.31 & 13.14 \\
4 & 12.46 & 18.24 & 12.93 & 25.59 & 17.55 & 13.23 \\
6 & 12.76 & 18.05 & 11.98 & 25.38 & 19.07 & 12.65 \\
\hline
\end{tabular}


Table S3. Equilibrium Dimer Concentrations in the presence of $\mathrm{A}^{\prime} \mathrm{C}^{\prime}$

\begin{tabular}{ccccccc}
\hline & \multicolumn{7}{c}{ Product mixture (mol\%) } \\
\cline { 2 - 7 } Time, h & AA & AC & CC & AB & BC & BB \\
\hline 1 & 11.02 & 22.30 & 14.53 & 15.93 & 23.18 & 13.05 \\
2 & 8.991 & 22.08 & 13.21 & 18.59 & 27.59 & 9.548 \\
3 & 9.284 & 21.79 & 13.09 & 18.67 & 27.34 & 9.834 \\
4 & 9.589 & 22.18 & 12.46 & 19.12 & 26.91 & 9.745 \\
5 & 9.017 & 20.84 & 11.96 & 20.17 & 27.79 & 10.21 \\
6 & 9.425 & 23.27 & 13.29 & 18.31 & 26.07 & 9.636 \\
& & Starting from AB, BB and CC & \\
1 & 9.608 & 17.25 & 13.13 & 25.67 & 23.07 & 11.28 \\
2 & 8.879 & 22.30 & 12.98 & 18.72 & 27.56 & 9.567 \\
3 & 9.634 & 21.66 & 12.89 & 18.41 & 27.27 & 10.13 \\
4 & 9.483 & 21.15 & 12.43 & 19.08 & 28.05 & 9.814 \\
5 & 9.325 & 21.33 & 12.17 & 18.69 & 28.63 & 9.848 \\
6 & 9.455 & 22.69 & 13.22 & 18.39 & 26.18 & 10.07 \\
\hline
\end{tabular}


Table S4. Equilibrium Dimer Concentrations in the presence of $B^{\prime} C^{\prime}$

\begin{tabular}{ccccccc}
\hline & \multicolumn{7}{c}{ Product mixture (mol\%) } \\
\cline { 2 - 7 } Time, h & AA & AC & CC & AB & BC & BB \\
\hline & 13.62 & 23.76 & 15.75 & 14.92 & 20.29 & 11.66 \\
2 & 9.738 & 26.63 & 12.70 & 19.47 & 22.28 & 9.183 \\
3 & 9.380 & 27.33 & 13.37 & 18.32 & 22.36 & 9.236 \\
4 & 10.01 & 26.93 & 12.92 & 19.35 & 21.34 & 9.454 \\
5 & 9.912 & 26.85 & 12.53 & 19.58 & 21.53 & 9.601 \\
6 & 9.908 & 26.29 & 12.60 & 19.35 & 22.20 & 9.650 \\
& 10.72 & 23.92 & 16.04 & 21.33 & 18.70 & 9.293 \\
1 & 10.75 & Starting from AA, AB and CC \\
2 & 9.762 & 27.29 & 12.56 & 19.55 & 21.55 & 9.297 \\
3 & 10.17 & 27.13 & 12.44 & 19.28 & 21.61 & 9.372 \\
4 & 9.776 & 26.24 & 12.62 & 19.31 & 22.59 & 9.459 \\
5 & 9.578 & 26.92 & 13.07 & 18.32 & 22.83 & 9.289 \\
6 & 9.816 & 27.16 & 12.93 & 18.86 & 21.93 & 9.305 \\
\hline
\end{tabular}

